\title{
EL ORIGEN DE LA HISTORIOGRAFÍA: HISTORICIDAD, ESCRITURA Y PLUS-DE-GOCE
}

\author{
Benjamín Mayer Foulkes \\ 17 Instituto de Estudios Críticos, México D.F., México
}

\begin{abstract}
RESUMEN: La naturaleza de la historiografía no puede ser esclarecida históricamente, sino sólo en el ámbito de la lectura. Utilizando como alegoría "El origen del mundo" de Gustave Courbet y su historia, tematizo el arjé de la historiografía y propongo que el objeto de la historiografía es el hiato permanente entre la historicidad y las historias que sin cesar intentan capturar su movimiento. Motivo por el cual la labor del historiógrafo guardaría una relación esencial con aquellas del desconstructor y del psicoanalista.
\end{abstract}

PALABRAS CLAVE: Historiografía, historicidad, différance, plus-de-goce, historia, desconstrucción, psicoanálisis, Courbet.

\section{A ORIGEM DA HISTORIOGRAFIA: HISTORICIDADE, ESCRITURA E MAIS-DE-GOZAR}

RESUMO: A natureza da historiografia não pode ser esclarecida historicamente, mas apenas no âmbito da leitura. Utilizando como alegoria "A origem do mundo" de Gustave Courbet e sua história, tematizo o arke da historiografia e proponho que o objeto da historiografia é o hiato permanente entre a historicidade e as histórias que permanentemente buscam capturar seu movimento. Motivo pelo qual o trabalho do historiador guardaria uma relação essencial com aqueles do deconstrutor e do psicanalista.

PALAVRAS-CHAVE: Historiografia, historicidade, différance, mais-de-gozar, história, desconstrução, psicanálise, Courbet.

\section{THE ORIGIN OF THE HISTOGRIOGRAPHY: HISTORICITY, WRITING AND PLUS-DE-JOUIR}

ABSTRACT: The nature of histogriography cannot be elucidated historically, but can be clarified in the domain of reading. Taking allegorical recourse to Gustave Courbet's "The origin of the world" and its colorful history, I thematize the Arkhe of historiography and propose the thesis that the object of historiography is the permanent hiatus between historicity and the histories that ceaselessly attempt to capture its movement. That is the reason why the task of the historiographer would be essentially related to that of the psychoanalyst and the deconstructor.

KEYWORDS: historiography, historicity, différance, plus-de-jouir, history, deconstruction, psychoanalysis, Courbet.

¿Cómo pensar la diferencia entre la historia y la historiografía? ¿Cómo arribar a su distinción y en qué términos articularla? ¿Cuál es el objeto de estudio de la historiografía? ¿Cómo ubicar recíprocamente la historia y la historiografía? ¿Cuál vendría lógica, e históricamente antes que la otra? ¿Cómo situar cada una respecto a la historicidad, entendida como su común condición de posibilidad? ¿Qué directrices desprender de nuestra tentativa de respuesta a estas interrogantes para las labores del historiógrafo y del historiador? ¿Cómo dar cuenta de la relación entre las labores del historiógrafo, el desconstructor y el psicoanalista?

Sinteticemos nuestras respuestas a tales preguntas a fin de anticipar al lector la perspectiva de este trabajo.
La diferencia entre la historia y la historiografía no puede ubicarse en el registro temático, archivístico o documental, sino sólo en el registro de la lectura. La historiografía opera a manera de suplemento crítico (esto es, a modo de un suplemento de lectura) que persigue a la historia por doquier como una sombra. Contra lo que la fórmula "suplemento de lectura" parecería sugerir, lejos de venir después de la historia, la historiografía tiene lugar a la vez que ésta, si no es que estrictamente antes, como su condición de posibilidad. De ahí que todo gesto histórico, toda obra de historia resulte ser, siempre ya, un efecto historiográfico.

Dicha precedencia lógica de la historiografía sobre la historia se debe a que la historiografía se ocupa la historicidad: el movimiento que posibilita e impo- 
sibilita toda historia. El movimiento de la historicidad es un efecto de la imposibilidad misma del presente y la presencia: se trata de un deslizamiento radicalmente irregular consecuencia del hecho de que ningún presente puede jamás coincidir plenamente consigo, estar plenamente presente a sí. Si todo presente es, de antemano, devenir de, y hacia otros presentes, la coincidencia consigo de la presencia y los presentes no es sino lo ahistórico mismo. Paradójicamente entonces, si bien la historicidad es aquello que posibilita toda historia (la articulación anhelante de la aprehensión de un presente, así se trate de un presente pasado o de un presente futuro), ninguna historia es capaz de saturar la historicidad. La historia es un efecto del redoblamiento sobre sí misma de la historicidad; la historia es la estela producida por la historicidad al permanecer sujeta su propia acción: la historia es la historicidad de la historicidad; la no coincidencia de la presencia y los presentes tampoco coincide consigo (no es una). La historia obligadamente surge ahí, en el elemento de la historicidad, donde de entrada es imposible.

Por consiguiente, todo intento de una historia estricta del origen (es decir, de la historicidad como origen de la historia), es vano: la historia no puede acceder a su propio origen. Por las mismas razones, resulta ilusorio pretender una historia de la, o las historias (como se ha definido clásicamente la labor del historiógrafo) que libre dicha imposibilidad. Muy por el contrario, el objeto de estudio de la historiografía es el hiato permanente entre la historicidad y las historias siempre diversas, singulares y transitorias que intentan articular, capturar, neutralizar, resistir o amaestrar la historicidad. La necesaria parcialidad de toda historia (su incompletitud, a la vez que su naturaleza interesada) es, de este modo, la propia orientación crítica de la historiografía, aquello que le concede su especificidad y con base en lo cual se sostiene en su peculiar promesa de una historia siempre por venir. Consecuentemente, la labor del historiógrafo es sin fin: la historia es $\sin$ fin... y también lo es su fracaso. Asimismo, la labor del historiógrafo se vuelve particularmente urgente ahí donde alguna historia cree haber logrado saturar la historicidad de la que ha pretendido hacerse cargo.

Todo lo cual sugiere que la intervención del historiógrafo (a partir de la historicidad) resulta afín a la del lector desconstructor (a partir de la différance constitutiva de la escritura, en el sentido de Derrida) como también a la del psicoanalista (a partir del plusde-goce [al que alude la letra $a$ ] que el analista dirige hacia el sujeto, como describe Lacan con su Discurso del Analista:

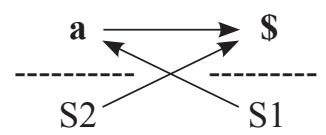

). Ello no a pesar, sino precisamente en virtud, de que la historiografía, la desconstrucción y el psicoanálisis no pueden más que problematizarse recíprocamente en la medida en que ninguno de ellos puede del todo abarcarse ni abarcar la integridad de sus [im]pares. Como la escritura y el plus-de-goce (que no es significantizable ni asimilable por el sujeto), la historicidad es conflicto, en primer lugar, consigo misma. Lejos de cancelarse o sustituirse recíprocamente, las intervenciones historiográficas, desconstructivas o psicoanalíticas se refuerzan en su singularidad. Lo cual no es sin consecuencias teóricas y estratégicas que han de tomarse en cuenta en el plano institucional. ¿Habrán de ser la universidad y los organismos de estado las sedes naturales del trabajo historiográfico, así como lo son hoy de la historia (que suele atenerse o bien a las exigencias del Discurso del Amo

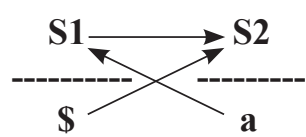

o bien del Discurso de la universidad

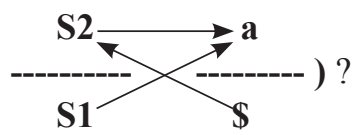

O por el contrario, ¿la historiografía se dispone a enfrentar el mismo desencuentro parcial con tales instituciones hasta ahora experimentado por el psicoanálisis y la desconstrucción?

\section{La interrogante}

Si la interrogante por la historiografía no puede dirimirse en el campo de la historia, campo que, como espero indicar, le sería derivado, entonces quizá debamos aproximarnos a ella por medio de una lectura, como la que a continuación propongo. Analizaré dicha interrogante en la escena abierta por El origen del mundo, el conocido óleo sobre tela pintado por Gustave Courbet en $1866 .{ }^{1}$

Me centro en El origen del mundo en virtud de que entiendo dicha obra como una intervención histórica y ya también historiográfica. El título del presente ensayo hace eco del nombre de la obra de Courbet. Ello con el fin de destacar que, a partir de dicha pintura, de lo que aquí se trata es de intentar una aproximación a la fuente, al linaje, al surgimiento, al proceder, en suma, al paradójico aparecer o hacerse visible de la historiografía. Asimismo, dicho título pretende aludir al extraño origen (la historicidad) al que atiende la historiografía, origen que estrictamente no puede concebirse más que como un no-origen. 


\section{La historia ${ }^{2}$}

El origen del mundo es un artefacto profusamente abordado en los términos característicos de la historia, que no son los de la historiografía ni mucho menos de la historicidad. Courbet nunca ha sido un artista cualquiera para los historiadores del arte: ¿cómo podría serlo quien originalmente zanjó la posibilidad de producciones posteriores como las de Manet, Renoir, Cézanne, Gaugin, Picasso, Duchamp, Warhol y Beuys? Por otra parte, son legión los registros de las peripecias del lienzo de El origen del mundo.

Comisionado originalmente por un diplomático turco coleccionista de arte erótico, el cuadro reapareció en Budapest donde fue confiscado por los nazis. Tras su derrota, la obra pasó a manos soviéticas. En 1955, fue comprada por el señor Jacques Lacan, quien murió en 1981 sin revelar su posesión del mismo. Posteriormente, los herederos del psicoanalista terminaron por donarla al parisino Musée d'Orsay a cambio de una paz fiscal (¿por qué de entre los múltiples tesoros de Lacan habrán escogido para tal propósito precisamente éste?); transmutado en un objeto público de culto comparable a la Mona Lisa en el Louvre, hoy El origen es celosamente vigilado por un flic. Asimismo, el óleo ha dado lugar a sin fin de interpretaciones teóricas cuya estructura las ubica asimismo en el plano de la historia. Doy de ello en seguida algunos ejemplos.

La imagen fue referida por Maxime du Camp, conservador de la época de Courbet, para atacar las tendencias políticas y estéticas (el "Realismo") de quien fuera amigo personal de Proudhon. Como polemiza du Camp:

Por algún olvido inconcebible, el artista que copió su modelo al natural, desatendió la representación de los pies, las piernas, los muslos, el estómago, las caderas, el pecho, las manos, los brazos, los hombros, el cuello y la cabeza. (Barzilai, 1999, p. 9-10)

En las antípodas del espectro político, en una circular de 1924 la Asociación de Artistas de la Rusia Revolucionaria suprimió cualquier referencia a este cuadro de Courbet, involuntaria e irónicamente subrayando así su importancia, para enaltecer la figura de su pintor, en el marco de su pugna contra las formas "decadentes" y "fracturadas" del arte Occidental (Cézanne, Derain, Picasso...) en los siguientes términos:

"el artista de hoy debe ser a la vez un maestro del pincel $\mathrm{y}$ un revolucionario que lucha por un mejor futuro para la humanidad. Sirva la figura trágica de Courbet como el mejor prototipo y recordatorio de los fines y faenas que el arte contemporáneo es llamado a resolver." (Harrison \& Wood, 1994, p. 385-387)

La primera vez que El origen del mundo apareció en una antología fotográfica publicada, a fines de la déca- da de los 1960, fue en libros de sexología y pornografía: no de arte. (Barzilai, 1999, p. 10) Y este cuadro también ha sido utilizado como evidencia en el marco de ciertas interpretaciones psicobiográficas de su autor:

“exponiendo gráficamente la propia falta de falo temida por el varón, en especial de uno tan preocupado por la virilidad como Courbet, la pintura puede considerarse como un repudio a la vez que un reconocimiento cuasiterapéutico de ese temor. (Rubin, 1998, p. 208)

Asimismo, El origen del mundo también ha sido considerado por una investigadora feminista como la encarnación del presunto "falocentrismo" de quien la detentara en secreto durante más de un cuarto de siglo:

El origen simultáneamente participa en un patrón de misoginia en que el arte no puede ser fácilmente diferenciado del fetichismo, la pornografía o la profanación del cuerpo femenino a la vez que se ubica fuera o más allá de ese patrón... Como una mujer lectora de Lacan, no tengo... una posición fija o final sobre esta cuestión... Esta incertidumbre podría denotar la debilidad y fragilidad (en otras palabras, la estructura "femenina") de un carácter lector condicionado por el registro paterno simbólico. Puede ser adicionalmente complicada por las complejidades de la propia posición lacaniana, que sostiene el falo a la vez que, por decirlo así, lo corta de tajo." (Barzilai, 1999, p. 18)

Ahora bien, más allá de estos ejemplos, también puede considerarse a El origen del mundo como una intervención en el plano de la historia porque su acto mismo habría sido conscientemente consumado por su autor en dicho plano. Courbet se esmeró siempre en inscribirse en su momento histórico. Leamos, por ejemplo, un fragmento de su Manifiesto de 1855:

“El título de Realista me fue impuesto así como el título de Romántico fue impuesto a los hombres de 1830. Jamás los títulos han brindado una idea precisa de las cosas; de otra manera, las obras serían superfluas.... He estudiado, aparte de cualquier sistema preconcebido y sin prejuicios, el arte de los antiguos y los modernos... Sólo he querido derivar de un conocimiento completo de la tradición una comprensión razonada e independiente de mi propia individualidad. Saber a fin de ser capaz, ésa era mi idea. Poder traducir las costumbres, las ideas, la apariencia de mi época según mi propia apreciación de la misma, (ser no solamente un pintor sino un hombre), en síntesis, crear arte viviente, ése es mi objetivo." (Barzilai, 1999, p. 157-158)

La apuesta histórica de este artista se jugó reiteradamente en dos ejes simultáneos y relacionados: el de su involucramiento político y el de su propuesta estética. En lo político, una vez establecida la Comuna de París de 1871, Courbet fue nombrado como el encargado de resguardar las colecciones artísticas de la Capital (más tarde fue acusado de permitir la destrucción de 
la columna triunfal de Napoleón en la Place Vendôme, y condenado a pagar su reconstrucción, hecho que le valió su destierro a Suiza, donde murió algunos años después). En lo estético, El origen del mundo se inscribe dentro de la tendencia más amplia de la subversión del desnudo femenino como representación espiritual, en dirección de la liberación de su carga sexual y ominosa. Como se interroga James Rubin en relación con el diálogo establecido por Courbet con el canon del desnudo:

“¿Significa esto que Courbet finalmente había aceptado, al menos en un cierto grado, valores contra los cuales había luchado tan vigorosamente? ¿O significa simplemente que había llegado a un entendimiento de su posición en la historia del arte?" (Rubin, 1998, pp. 212-216)

El origen del mundo no sólo ha sido masivamente historiado por teóricos y profesionales de la historia: el acto mismo que le dio origen tuvo como horizonte el discurso de la historia.

\section{La historiografía}

¿En qué sentido es, entonces El origen del mundo asimismo una intervención en el plano historiográfico? El hecho mismo de la multiplicación de los discursos de historia acerca de este cuadro tiene el efecto de suspenderlos en conjunto y de consignar su insuficiencia última: cualquier perspectiva histórica acerca de $E l$ origen del mundo se enfrenta a toda suerte de consideraciones que anteceden y complican sin remedio su apropiación histórica definitiva. Desde luego, podría sostenerse lo inverso: que, lejos de obstaculizar la labor de historiar, la inagotable historicidad de esta tela es el clamor mismo de las miradas y los discursos de historia. Y sí. Pero con la única y crucial salvedad de que, en el momento mismo en que la obra abre y se abre al plano de lo histórico, El origen del mundo lo desborda y lo excede sin retorno. El origen del mundo rebasa lo histórico precisamente en virtud de que lo convoca: la obra supera la potencia de sus apropiaciones históricas ulteriores tanto como el mismo imaginario histórico del pintor que la trajo a la luz. Porque la sombra de la historicidad que pone en marcha toda historia (del que el propio cuadro es a su vez efecto) reside aún en ella, y ningún historiador, cualquiera que sea su credo, será capaz de lograr su evicción.

En principio, todas las obras de Courbet, así como las que, según los historiadores del arte, le anteceden y le suceden, serían comprendidas por el horizonte (i) lógico de El origen del mundo. Lo mismo podría decirse acerca de todo acto de creación y procreación en general: El origen del mundo los abarca y los rebasa. No porque El origen del mundo sea una obra intemporal sino, al contrario, porque su historicidad es irreductible. De hecho, la historicidad es la efectividad misma de $E l$ origen del mundo (así como de toda imagen en general, en la medida en que está esencialmente constituida por la disyunción y el exceso: bien señala Merleau-Ponty que "lo imaginario es incoherente o improbable porque es imaginario, y no es imaginario porque es incoherente". (Merleau-Ponty, 1975, p. 61) Así, podríamos postular que la efectividad de esta obra, entendida como subversión del desnudo "espiritual", consiste precisamente en una invocación de la historicidad excesiva y su encarnación en una representación sexual no menos insoportable que atractiva. Según esta perspectiva, El origen del mundo es una obra significativa en la medida en que desmonta aquella larga tradición estética en que el desnudo es figurado como un ideal; que tal desmontaje sea efectivamente posible se debe a que ninguna representación es capaz de saturar la historicidad del cuerpo.

Este cuadro que se concierne con el plano de la historia invoca, y de momento también materializa, la historicidad como su propio origen. Es en la medida en que El origen del mundo subvierte todas sus posible apropiaciones históricas que consiste en una intervención historiográfica.

\section{La historicidad}

Origen del origen, la historicidad sólo puede inferirse por sus secuelas. ¿Pues qué habría antes, atrás del origen del mundo? Paradoja: El origen del mundo es originado por aquello que su título designa, pero eso originante permanece en la penumbra. Lo mismo puede afirmarse en relación con la imagen: como cuerpo sexuado (se ha sostenido categóricamente que en esta obra figura la mujer después de "las convulsiones del amor") (Roudinesco, 1995, p. 273), o como cuerpo materno, El origen del mundo remite a un origen (libidinal o biológico: el sexo, la maternidad); a la vez, aquello efectivamente plasmado en tal representación resulta ser una secuela de ese mismo origen representado. Este icono del origen termina así remitiendo a un antes inaccesible a nuestra mirada. $E l$ origen del mundo alude a la extraña topología de todos los orígenes; el origen del mundo es la fuente de todos los orígenes en general, el Origen por excelencia, por consiguiente es la posibilidad misma de todos los discursos imaginables de historia acerca de esta obra. El cuadro finge representar aquello de lo que a su vez es el efecto: allí el Origen se figura a sí mismo a posteriori; simula hacer un tema entre otros de aquello que no puede ser un tema porque es la posibilidad misma de la delimitación (temática). Simulándose es como, en El origen del mundo, el Origen se disimula. 
Ante este cuadro, las identificaciones subjetivas imaginarias que aspiran a una estabilización no encontrarán descanso: frente a la imagen miro tanto como soy mirada. Al no haber fundamento histórico último, la situación propia (y la situación de lo propio en general, en el sentido de lo propiamente presente-a-si) se torna indecidible. Todo discurso de historia es, de una u otra forma, efecto de aquello que relata; el relato mismo de una historia vela lo relatado, simula brindar lo invisible mismo a la mirada. Historiador, traidor. El Origen, la historicidad, es lo invisible mismo (considérese la duplicidad del término "historia" que remite a lo "realmente acontecido" tanto como a su "relato"). La historia, velo de la historia. En alguna ocasión Courbet se negó a pintar un ángel por no haber visto nunca uno: ¡qué paradoja aquella de que los límites de la representación (del Origen) puedan resultar aún más dramáticamente plasmados por una estética realista que por una estética vanguardista, en apariencia tanto más consonante con la historicidad inabarcable! De donde la radicalidad del Realismo, como también del Empirismo y del Positivismo, que de nada carecen ante las imaginables historias surrealistas, expresionistas o existencialistas que, según Hayden White, aún no han sido intentadas por los historiadores modernos a pesar de su gran capacidad artesanal (Holly, 1995, p.67). La radicalidad de las historias realistas, empiristas y positivistas es en cierto modo mayor que la de cualquier historia surrealista, expresionista o existencialista: el inaprehensible movimiento de la historicidad no es menos constitutivo, ni más abarcable, por las historias "vanguardistas" que por las otras. Por el contrario, a menudo las historias vanguardistas prometen (por vía negativa) el cumplimiento de aquello que, en rigor, ninguna historia puede consumar: la articulación sin resto de la historicidad. ¿Entonces qué habría antes, atrás, del origen del mundo? Siempre podrá plantearse tal pregunta, pero a su respuesta siempre se interpondrá el lienzo que la provoca en primer lugar. El origen es un no-origen... del Origen en primer lugar.

Así como El origen del mundo falla respecto a su propia promesa de representar el origen del mundo, así también la condición necesaria de toda historia es fallar (como hacen los jueces); y de hacerlo, de preferencia, prolíficamente. De donde la historiografía, entendida como la lectura atenta de este fallar, tiene precedencia lógica sobre la historia. Toda historia se precipita al lugar de un vacío: el cometido de la historiografía es ubicar y bosquejar este vacío. La historiografía no se enfrenta sin más a la historia en nombre de la historicidad, sino que se limita a identificar en ella sus fallas de origen (como suele aclarar el televisor cuando la transmisión es defectuosa). El acto historiográfico no es algo que el historiógrafo haga a la historia: por el contrario, la historicidad que orienta la labor del historiógrafo se da a leer ahí donde un discurso de historia ha tenido lugar por efecto suyo. Si la historiografía opera a manera de un suplemento crítico, un suplemento de lectura que persigue a la historia por doquier como una sombra, no podemos obviar la referencia a que, en Occidente, los mitos de origen tanto de la pintura como de la filosofía parten justamente de la sombra. Me refiero al mito de Plinio el Mayor, según el cual la pintura dio inicio como delineamiento de la sombra humana, y al mito platónico de la caverna en que la realidad sólo es inferida la proyección de sus sombras. En Occidente la representación y el pensamiento nacen también "en negativo" (Stoichita, 1997, pp. 7-8) ¿Cómo no habrían de hacerlo la historia a partir de la historicidad y la historiografía como el saber que de su sombra (la historicidad) se ocupa? La historia es el verdadero suplemento de la historiografía, que sólo aparece retrospectivamente como el suplemento de ésta.

\section{El origen de la historiografía}

Preguntemos: ¿cuál es el origen de la historia surgida del elemento mismo de su desengaño originario?, ¿cómo acaece la historia por efecto de la historicidad? El enigma de la historicidad no es la propia historicidad, ni tampoco la historiografía como aquello que de ella se encarga. El verdadero enigma de la historicidad es la historia que se origina en su seno y que no hace más que resistirse a aquello que le dio a luz. Pues la historia no es nunca sino el intento, siempre fallido, de reducir, comprehender o neutralizar el vértigo de la historicidad. Concebidas en términos de la lectura, la relación entre la historia y la historicidad puede caracterizarse, así, de acuerdo con lo señalado por Paul de Man acerca de la llamada "lectura" universitaria y escolar (lectura que aquí correspondería al discurso de la historia), entendida como una resistencia a la lectura en todo el sentido de la palabra; pues esta "lectura" se empeña en sostener sentidos (imaginarios) a contracorriente del poderoso sustrato retórico del texto que siempre los torna parciales y estrictamente insostenibles. (De Man, 1990) Porque en rigor la lectura no es sino la disolución de dichos sentidos: contra toda ideología canónica de la lectura enfrentamos el hecho de que a más lectura, menos comprensión (porque en toda lectura efectiva la equivocidad del lenguaje pasa a primer plano) e, inversamente, de que a menos lectura, más comprensión, puesto que de este modo los "sentidos" del texto aparecen más "nítidos". El aparato universitario-escolar resulta ser un gigantesco transmisor de consensuadas deslecturas (misreadings). Si la historicidad es la no coincidencia del presente consigo mismo, en cambio la historia es la huella de la no coincidencia de esta no coincidencia del presente consigo mismo. La historia es una producción de segundo 
grado respecto a su origen imposible. La historia es el sedimento de la historicidad, su margen y su desecho: precisamente por eso está al centro de la operación de dicha historicidad, y también por eso la historia está en el centro de la operación de la historiografía.

La historicidad no puede del todo articularse, capturarse, neutralizarse, resistirse o amaestrarse; toda afirmación del "fin de la historia" tendrá siempre un carácter hilarante pues el "fin de la historia" supondría la posibilidad de un presente definitivo. Empero, el fin (el objetivo) de toda historia es precisamente el fin (la muerte) de la historia, el dominio definitivo de la historicidad. No podría ser de otra manera: la historia es la marca de la historicidad irreductible de la propia historicidad. La necesaria, estructural y (des)estructurante no coincidencia de esa no coincidencia del presente consigo mismo que es la historicidad hace de la historia una posibilidad perenne y obligada. De ahí que el locus, el tópico (el lugar, el tema) discursivo, de la historiografía y la historia sea siempre compartido-en-disyunción. Por eso la diferencia entre la historia y la historiografía no puede ubicarse en el registro temático, archivístico o documental, sino sólo en el registro suplementario de la lectura. La diferencia entre el plano histórico y el plano historiográfico de lectura de El origen del mundo no requiere de un cambio en la escena de lo imaginario y visible. La lectura historiográfica conduce la lectura histórica hasta sus últimas consecuencias, hasta aquél punto en que se revelan absolutamente derrotadas sus premisas presencialistas. La labor del historiógrafo es sin fin precisamente porque la historia es sin fin. Y es particularmente urgente ahí donde alguna historia cree haber logrado saturar la historicidad de la que ha creído hacerse cargo. En este sentido, el nombre historiografia condensa con precisión aquello que en ella permanece en juego: la historiografía se ocupa de la grafía histórica, es decir, del carácter escrito de la historia (el movimiento característico de la escritura es el movimiento de la diferencia-en-repetición, la différance), carácter que es su simultánea condición de posibilidad e imposibilidad, independientemente de que se trate de una historia efectivamente escrita en el sentido ordinario del término. Historicidad y escritura son nociones del mismo orden (la diferencia-en-repetición es otra manera de consignar la imposibilidad de la presencia que es la propia historicidad): el historiógrafo enfrenta, en nombre de la grafia, los semblantes (por excelencia pertenecientes al terreno de la historia) ordinariamente asociados con el logocentrismo.

\section{La historiografía del origen}

Estrictamente, entonces, en tanto que estudiosa de la historicidad, o de sus efectos, la historiografía no queda limitada al campo de la historia; de ahí que no pueda, ni deba, ser concebido como un campo meramente auxiliar de ésta. Ante la pregunta, ¿cuál es entonces la consistencia de la historiografía?, la respuesta es simple y compleja a la vez. Si el campo de análisis de la historiografía es la impropiedad histórica de la historia (en el plano diacrónico tanto como en el sincrónico, pues tal distinción es secundaria respecto a la imposibilidad de la presencia), ella misma no tiene y no puede tener un objeto propio de estudio: la historicidad que la anima es, por definición, impropia. La historicidad en cuyo nombre opera el historiógrafo hace serie con la différance derridiana y el plus-de-goce lacaniano, no menos que con todos los otros nombres de aquello innombrable que posibilita los efectos nominales. Si nos valemos de nueva cuenta de las grafías propuestas por el psicoanalista francés para transmitir su doctrina de los Cuatro discursos (aun si hacemos un uso poco ortodoxo de ellas), ${ }^{3}$ bien podríamos consignar que, en la medida en que el lazo psicoanalítico al que nos referimos se escribe así:

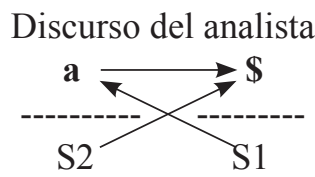

y tomando en cuenta la propuesta de que la desconstrucción no es una mera filosofía ni un método de lectura sino un lazo social (en el sentido de Lacan) con dos expresiones complementarias a la vez que tirantes e indecidibles (que denomino "Desconstrucción subjetivante" y "Desconstrucción instituyente"): ${ }^{4}$
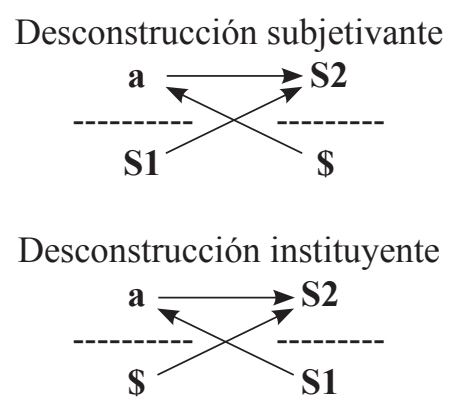

entonces podemos afirmar que la historiografía que aquí interesa, responde a la siguiente descripción (de hecho, una indecidible doble descripción: una "Historiografía subjetivante" que reabre un lugar para el sujeto al horadar los imaginarios de cierta historia y una "Historiografía reconfigurante" capaz de producir nuevas perspectivas y relatos en el momento mismo en que hace caer el gran relato de la historia): 
Historiografía subjetivante

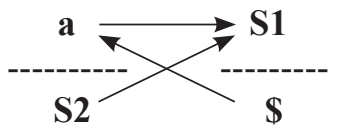

Historiografía reconfigurante

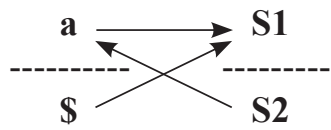

Lo cual tiene consecuencias teóricas y estratégicas fundamentales que deben considerarse en el plano institucional, con miras a la facilitación de la mutua lectura e interpelación de estas tres esferas: la historiografía, la desconstrucción y el psicoanálisis.

Llegados a lo cual, el problema que asoma atañe a los propios marcos institucionales desde los cuales es posible poner en práctica lecturas e intervenciones en nombre de la historicidad. La historia es una disciplina con un arraigo tradicional en la universidad, así como en los organismos de Estado: pareciera, entonces, que no se presenta disyuntiva alguna. Pero si efectivamente la historiografía hace serie con la escritura de la que se ocupa la desconstrucción y con el plus-de-goce del que se ocupa el psicoanálisis, entonces las historias y los destinos institucionales de la desconstrucción y del psicoanálisis no pueden más que resultar indiscutiblemente pertinentes para el historiógrafo.

Con lo cual, son demasiadas las interrogantes provocadas para abordarlas aquí. Baste recordar que a diferencia del psicoanálisis, la desconstrucción nunca ha pretendido la constitución de una institución propia. La aporética de la institución psicoanalítica es bien conocida ("El entrenamiento institucional probablemente sea antitético al análisis") (Limentani, 1974, p. 72) como también es bien conocida la aporética de la actividad desconstructiva desarrollada en la universidad:

"Pero, ¿cómo negarlo? Hay cosas que no se pueden decir en la universidad, ni fuera de ella. Hay ciertas maneras de decir ciertas cosas, que ni son legítimas ni están autorizadas. Hay, simplemente, "objetos" que no se pueden estudiar, analizar, trabajar, en ciertos departamentos universitarios. La censura no consiste, por otra parte, en reducir al silencio absoluto. Es suficiente con que limite el campo de los destinatarios o de los intercambios en general. Hay censura desde el momento en que ciertas fuerzas (vinculadas a poderes de evaluación y a estructuras simbólicas) limitan, simplemente, la extensión de un campo de trabajo, la resonancia o la propagación de un discurso... la censura que pesa sobre la universidad o que procede de ella (pues la universidad es siempre censurada y censurante), este poder interdictor, se encuentra asociada a otras instancias: otras instituciones de investigación y de enseñanza, nacionales o internacionales, el poder editorial, los media, etc.” (Derrida, 1995, p. 89)
En el fondo, ambas aporéticas son efecto de aquel dilema sucintamente expresado por el siguiente koan: "Cuando mueren tu padre o tu madre, díselo al Buda; pero cuando muere el Buda, ¿a quién se lo dices?”. Ambas vías, la institucional y la extrainstitucional tienen ventajas y desventajas de las que habría que dar cuenta, histórica e historiográficamente. La pregunta que queda abierta es aquella por la modalidad institucional más adecuada para la labor historiográfica. ¿Su modalidad institucional debe asemejarse más a la del psicoanálisis o más a aquella asociada hasta ahora con la desconstrucción? ¿Existen acaso otras posibilidades?

Termino con la anticipación de una objeción a mi argumento. Se podría sostener que mi razonamiento es capcioso porque El origen del mundo es un objeto autorreflexivo. Ciertamente lo es, pero todo objeto (cultural, significante) lo es también, actual o virtualmente. $\mathrm{O}$ bien, inversamente, según la perspectiva que adoptemos, no lo es ninguno (tampoco El origen del mundo). Todo objeto es producto de una repetición y se repite a sí mismo en abismo; a la vez, todo objeto es marcadamente singular, hasta el punto de diferir también de sí. Dicho de otro modo, todo objeto cabe en sus propias categorías y por eso mismo las excede; a la vez, todo objeto o texto desborda su contexto, las categorías de las que está constituido: de otra manera su singularidad se vería suprimida por sus marcos de referencia. Como asevera con Wittgenstein Lacan:

"No se puede decir nada que no sea tautológico... Sean cuales sean los hechos del mundo... sea lo que sea lo que de ellos enunciamos, lo que constituye el mundo es la tautología de la totalidad del discurso." (Lacan, 1992, p. 63)

Y si ningún enunciado puede evitar ser tautológico estrictamente la tautología no existe. Así que la presente descripción de El origen del mundo efectivamente aspira a ser paradigmática de todo objeto en general, es decir, de todo objeto en tanto que histórico, efecto de historicidad.

\section{Notas}

1 El origen del mundo, de Gustave Courbet, puede ser visitada en el sitio web del Musee d'Orsay, París: www.musee-orsay.fr.

2 Para un desarrollo más detallado de la relación entre "historia" e "historicidad", refiero a Mayer Foulkes, Benjamín "Perdurabilidad de la historia en Jacques Derrida", en: Von Wobeser, G. (coord).(1998) Cincuenta años de investigación histórica en México. México: UNAM. pp. 59-67.

3 Mi defensa de ese uso poco ortodoxo es objeto de un proyecto en curso, cuya primera presentación tuvo lugar bajo la forma de la conferencia "Más allá de los cuatro discursos de Jacques Lacan" en el marco del coloquio "Política y psicoanálisis", organizado por Invención del Psicoanálisis S. C. en El Colegio de México el 27 de septiembre de 2003. (Inédita) 
4 Conferencia "Desconstrucción: lazo social" en el coloquio: "Derrida: pasiones institucionales", Facultad de Filosofía y Letras de la Universidad Nacional Autónoma de México, México, 24 de octubre de 2005. (Inédita)

\section{Referencias}

Barzilai, S. (1999). Lacan and the Matter of Origins. Palo Alto, CA: Stanford University Press.

De Man, P. (1990). La resistencia a la teoría. In P. De Man, La resistencia a la teoría. (E. Elorriaga \& O. Francés, trads., pp. pp.11-37). Madrid: Visor.

Derrida, J. (1995). Cátedra vacante: censura, maestría y magistralidad. In J. Derrida, El lenguaje y las instituciones filosóficas (Grupo Decontra, trads.. pp. 85-111). Barcelona-Buenos Aires-México: Paidós/I.C.E de la Universidad Autónoma de Barcelona.

Harrison, C. \& Wood, P. (1994). Art in Theory: 1900-1990. An Anthology of Changing Ideas. Cambridge, MA: Blackwell.

Holly, M. (1995). Past Looking. In S. Melville \& B. Readings (Eds.), Vision and Textuality.(pp. 67-89). London: Macmillan.

Lacan, J. (1992). Seminario del 21 de enero de 1970. In El seminario de Jacques Lacan, Libro 17: El reverso del psicoanálisis. (pp. 57-72). Barcelona-Buenos Aires-México: Paidós.

Limentani, A. (1974). The Training Analyst and the Difficulties in the Training Psychoanalytic Situation. International Journal of Psychonalysis, 55, pp. 71-77.

Mayer Foulkes. B. (1998). Perdurabilidad de la historia en Jacques Derrida. In G. Von Wobeser (Coord), Cincuenta años de investigación histórica en México (pp. 59-67). México: UNAM.

Merleau-Ponty, M. (1975). Lo visible y lo invisible. Madrid: Seix Barral.
Roudinesco, E. (1995). Lacan. Esbozo de una vida, historia de un sistema de pensamiento. (T. Segovia, trad.). México: Fondo de Cultura Económica.

Rubin, H. (1998). Courbet. Arte e ideas. Nueva York: Phaidon. Stoichita, V. (1997). A Short History of the Shadow. Londres: Reaktion Books.

Benjamín Mayer Foulkes es psicoanalista. Es el director fundador de 17, Instituto de Estudios Críticos, así como del postgrado en Teoría Critica de esa institución. Entre 1995 y 2002 fundó y dirigió la Maestría en Semiótica de la Universidad Anáhuac. Formado en el Reino Unido y en México, obtuvo la licenciatura en Historia y la maestría en Teoría Crítica por la Universidad de Sussex y el doctorado en Filosofía por la UNAM. Llevó a cabo su primera formación en psicoanálisis en el Centro de Investigaciones y Estudios Psicoanalíticos. Docente en México y el extranjero en departamentos de historia, letras, artes y psicología, ha sido corresponsal del Collège International de Philosophie, Francia. Como autor, sus trabajos sobre semiótica, filosofía, arte, historia y psicoanálisis han sido publicados en español, inglés, italiano, francés y turco. Dirección: Av. Revolución 1500, Colonia Guadalupe Inn, México D.F. C.P. 04100. Correo electrónico: bmayer@17.edu.mx

\section{El origen de la historiografía: historicidad, escritura y plus-de-goce}

Benjamín Mayer Foulkes

Recebido em: 13/10/2008

Revisão em: 20/06/2009

Aceito em: 21/06/2009 